Results: In all women in whom glucose decreased ( $n=138)$, insulin release was satisfactory at $1 \mathrm{~h}$. The remaining women had apparent ongoing absorption with increased incremental glucose concentration; 77 of these had insulin release at $1 \mathrm{~h}$ (no retesting required); 38 had markedly delayed glucose absorption with low initial insulin release (retesting required) and 69 showed some insulin release ongoing at $1 \mathrm{~h}$ continuing to increase at $2 \mathrm{~h}$ (immediate retesting not helpful). In a very small number $(n=8)$ neither glucose absorption nor insulin release were demonstrated.

Discussion: In 330 studied flat OGTT, we identified that reflex insulin testing was not needed in $42 \%$. Reflex insulin testing demonstrating glucose absorption saved $23 \%$ of 330 women a repeat OGTT.

\section{ANALYSIS OF QUALITY IMPROVEMENT FORMS IN DEPARTMENT OF CLINICAL CHEMISTRY IN SRI LANKAN TERTIARY CARE REFERENCE LABORATORY}

Harsha Samarasekara, Saroja Siriwardena, Sandeepani Gunawardena, Susantha Liyanage, Nadie Perera, Chandana Padmakantha

Lanka Hospital Diagnostics, Colombo, Sri Lanka

Lanka hospital diagnostics (LHD) is ISO 15189 Accredited tertiary care reference laboratory, offering general and specialised tests in clinical chemistry. In July 2014 the test menu of this laboratory was upgraded by provision of state of the art analysers and provision of high level supervision by a fulltime specialist chemical pathologist. The quality management system of LHD has also been upgraded in line with higher level of international accreditation standards such as JCIA and CAP.

Aims of this study:

1. To identify basic deficiencies (pre-analytic, analytic and postanalytic errors present in the clinical chemistry laboratory.

2. Education of all stakeholders about specific corrective and preventive measures.

3. To create a data base where regular data analysis is performed and required interventions carried out regularly.

Method: Fifty-five quality improvement forms received by clinicians and patients were analysed. Deficiencies identified during routine work were also actively reported by technical and quality team.

Results: The majority of quality improvement forms received by the whole laboratory were lodged by department of clinical chemistry (33.4\%); pre-analytical errors (30.9\%), analytical errors $(12.7 \%)$, post-analytical errors $(16.4 \%)$, no errors $(34.5 \%)$ and administrative/safety issues $(5.4 \%)$ were identified.

Common errors included following: communication gap between laboratory and clinicians, sample identification errors, report delays, sample collection errors for specialised tests, lack of clinician's contact details to inform critical values, test ordering errors, sample transport errors, transcription error, incorrect reference ranges, methodological errors, IT networking error and report formatting error.

Discussion: Each deficiency has been identified. Root cause analysis and corrective actions were done in real time. Preanalytical error rates were $<0.01 \%$, comparable with literature from developed countries. Every effort will be taken with the highest level of management commitment to prevent such errors in future. Laboratory staff, phlebotomist, nursing and all stake holders will be regularly educated.

\section{IMMERSION OF BOVINE EYEBALLS AFTER ONE HOUR IN SEAWATER DOES NOT RESULT IN ELEVATION OF POST-MORTEM VITREOUS HUMOR SODIUM AND CHLORIDE LEVELS}

\section{S. Anne, R. Tse, C. Oldmeadow, A. Cala}

Department of Forensic Medicine, Newcastle, Forensic and Analytical Science Service (FASS), NSW Health Pathology, John Hunter Hospital, Newcastle, NSW, Australia

Background: Elevations in post-mortem vitreous sodium chloride (PMVSC) levels may help differentiating seawater drowning deaths from immersion deaths not related to drowning. It is unclear whether the elevation is related to blood electrolyte changes following inhalation of seawater, or due to passive electrolyte diffusion or osmosis across the outer coats of the eye during immersion.

Aim: To investigate the changes in bovine PMVSC at different time points whilst immersed in seawater.

Methods: Forty-eight bovine eyes were obtained from an abattoir and randomised into two groups: (a) submerged in seawater ('wet group') or (b) placed in an impermeable plastic bag immersed in seawater ('dry group'). The PMVSC from six eyeballs were measured from each group (without replacement) at 30 minutes, 1 hour, 6 hours and 12 hours.

Results: There was no significant difference in mean PMVSC between the two groups at 30 minutes and 1 hour intervals. Significant difference was noted from 6 hours onwards.

Discussion: Bovine PMVSC levels remain constant when immersed in seawater for up to 1 hour. Assuming similar physical properties in humans, elevations in PMVSC in bodies immersed in seawater for less than 1 hour would not be due to passive electrolyte diffusion or osmosis across the outer coats of the eye.

\section{SUBARACHNOID HAEMORRHAGE DUE TO ANEURYSMAL RUPTURE SECONDARY TO FIBROMUSCULAR DYSPLASIA}

J.M. Dyke $^{1}$, D.M. Moss ${ }^{2,3}$, V.A. Fabian ${ }^{1,3}$

${ }^{1}$ Neuropathology, PathWest, Royal Perth Hospital, ${ }^{2}$ Forensic Pathology, PathWest, QEII, Perth, and ${ }^{3}$ School of Pathology and Laboratory Medicine, University of Western Australia, WA, Australia

Case report: A 26-year-old female was found deceased at home in bed, with subarachnoid haemorrhage identified as the cause of death on post-mortem examination. On macroscopic examination of the brain there was a small aneurysm of the anterior communicating cerebral artery with probable rupture, associated with widespread subarachnoid haemorrhage. Histology of the circle of Willis and major branches confirmed the ruptured aneurysm, secondary to a non-inflammatory 